\title{
Epigenetic inactivation of the extracellular matrix metallopeptidase ADAMTS19 gene and the metastatic spread in colorectal cancer
}

Sergio Alonso ${ }^{1}$, Beatriz González ${ }^{1}$, Tatiana Ruiz-Larroya ${ }^{1,2}$, Mercedes Durán Domínguez ${ }^{3}$, Takaharu Kato 1,4, Akihiro Matsunaga ${ }^{2}$, Koichi Suzuki ${ }^{4}$, Alex Y. Strongin ${ }^{2}$, Pepita Gimènez-Bonafé ${ }^{1,5}$ and Manuel Perucho ${ }^{1,2,6^{*}}$

\begin{abstract}
Background: ADAMTS19 encodes a member of the ADAMTS (a disintegrin and metalloproteinase domain with thrombospondin motifs) protein family with emerging roles in carcinogenesis and metastasis. ADAMTS shares several distinct protein modules including a propeptide region, a metalloproteinase domain, a disintegrin-like domain, and a thrombospondin type 1 (TS) motif. In a previous work, we found ADAMTS19 frequently hypermethylated in colorectal cancer (CRC). We explored the association of methylation with tumor genotype and phenotype.

Results: The methylation status of the CpG island in the promoter of ADAMTS19 was determined in 252 colorectal, 65 pancreatic, 33 breast and 169 ovarian primary tumors, 70 CRC metastases, and 10 CRC cell lines. Tumor-specific methylation of ADAMTS19 was significantly more frequent in gastrointestinal than in gynecological cancers (odds ratio $(\mathrm{OR})=2.9$, confidence interval $\left.(\mathrm{Cl})=(1.9-4.7), p=5.2 \times 10^{-7}\right)$ and was independent of the methylation of adjacent loci in CRC. Hypermethylation associated with CRC with mutated BRAF oncogene $\left(\mathrm{OR}=10.1, \mathrm{Cl}=(3.1-42.9), p=6.3 \times 10^{-6}\right)$ and with the mucinous phenotype in $C R C(O R=2.1, C l=(1.1-4.1), p=0.023)$ and ovarian cancer $(\mathrm{OR}=60, \mathrm{Cl}=(16-346)$, $p=4 \times 10^{-16}$ ). Methylation was significantly more frequent in CRC metastases homing to the ovary and omentum than in those homing to the liver and lung $(\mathrm{OR}=6.1, \mathrm{Cl}=(1.8-22.2), p=0.001)$. Differentiating local from distant metastatic spread, methylation negatively associated with tumor progression $(p=0.031)$ but positively with depth of invasion $(p=0.030)$. Hypermethylation associated with transcriptional repression in CRC cell lines, and treatment with $5^{\prime}-A Z A-2^{\prime}-$ deoxycytidine led to reactivation of mRNA expression. shRNA-mediated silencing of ADAMTS19 had no effect on the in vitro proliferation rate of CRC cells but significantly diminished their collective migration speed $\left(56 \%, p=3.3 \times 10^{-4}\right)$ and potential to migrate in collagen I $\left(64 \%, p=4.3 \times 10^{-10}\right)$.
\end{abstract}

Conclusions: Our results highlight the frequent involvement of ADAMTS19 epigenetic silencing in CRC and mucinous ovarian cancer. The mechanistic preferences for the target organ of metastatic spread may lead to the development of diagnostic CRC biomarkers. The association with the mucinous phenotype also may have diagnostic applications for ovarian cancer.

Keywords: ADAMTS, Methylation, Matrix metallopeptidases, Gastrointestinal cancer, Ovarian cancer, MS-AFLP

\footnotetext{
* Correspondence: mperucho@imppc.org

${ }^{1}$ Institute of Predictive and Personalized Medicine of Cancer (IMPPC), Institut d'investigació en ciéncies de la salut Germans Trias I Pujol, (IGTP), Campus Can Ruti, 08916 Badalona, Barcelona, Spain

${ }^{2}$ Sanford Burnham Prebys Medical Dicovery Institute, 10901 N. Torrey Pines Rd. La Jolla, San Diego, CA 92037, USA

Full list of author information is available at the end of the article
} 


\section{Background}

Colorectal cancer (CRC) is the third most common cancer for men and women worldwide with over 1.3 million new cases diagnosed in 2012 [1]. Despite decreasing trends in incidence and mortality in the last decade, CRC still is the third cause of cancer-related deaths accounting for near $10 \%$ of total cancer mortality worldwide [1]. Metastatic disease is the major cause of death in CRC. The metastatic dissemination involves the acquisition by the malignant cell of an abnormal loss of the tridimensional homeostatic tissue organization. Metastatic spread is a complex multistep process that includes several sequential steps: invasion through the extracellular matrix (ECM), migration, epithelial-mesenchymal transition (EMT), angiogenesis, the ability to survive without the contact with other sister cells ("anoikis"), colonization, and resistance to adverse tissue environments [2, 3]. CRC metastasizes most commonly to the liver, the lung, and the peritoneal cavity, and the histological cancer subtypes and tumor location influence the patterns of metastatic spread [3, 4]. Dissemination of metastases in CRC can be roughly classified as via the lymphatic and circulatory systems to distant organs-rectal cancers with tendency for homing to the lung and colon cancers with preferential dissemination to the liver-or via local mesothelial spread of floating cancer cells to the peritoneal surfaces including the omentum and proximal organs [5]. While the first two dissemination ways involve intravasation and extravasation, the third may not, but little is known about the molecular mechanisms that may underlie these different metastatic spread behaviors.

Alterations in the ADAMTS (a disintegrin and metalloproteinase domain with thrombospondin motifs) extracellular matrix metallopeptidases contribute to tumorigenesis and tumor progression [6-8]. The human ADAMTS family encompasses 19 multidomain extracellular matrix metallopeptidases that participate in a wide range of physiological processes, including ECM assembly and degradation, homeostasis, organogenesis, and angiogenesis [7, 9]. The first member of this family, ADAMTS1, was cloned in 1997 during a screening of genes selectively expressed on a murine cachexigenic tumor cancer cell line [10]. Multiple other ADAMTS genes were later isolated and characterized by several groups [11-21]. ADAMTS enzymes are closely related to the members of the ADAM (a disintegrin and metalloproteinase domain) family of metallopeptidases. However, ADAMTS contain additional thrombospondin type 1 motifs (TSP1) in their sequence. TSP1 motifs are involved in the interaction with glycoconjugates such as heparin and heparan sulfate that are present in the ECM [22, 23]. The physiological substrates of the ADAMTS family members include the propeptides of type I collagen (ADAMTS2 and ADAMTS14), type II collagen (ADAMTS2 and ADAMTS143), aggrecan
(ADAMTS1, ADAMTS4, ADAMTS5, ADAMTS9, and ADAMTS12), versican (ADAMTS9), alpha-2-macroglobulin (ADAMTS12), and von Willebrand Factor multimers (ADAMTS13).

According to their physiological functions, ADAMTS proteins have been grouped into anti-angiogenesis (ADAMTS1 and ADAMTS8), aggrecanases (ADAMTS1, ADAMTS4, ADAMTS5, ADAMTS8, ADAMTS9, and ADAMTS15), procollagen N-proteinases (ADAMTS2, ADAMTS3, and ADAMTS14), GON-ADAMTS (ADAMTS9 and ADAMTS20), and the von Willebrand factor cleaving protease (vWCFP, ADAMTS13) [9]. The physiological function and the substrates of ADAMTS6, ADAMTS7, ADAMTS12, and ADAMTS16 to ADAMTS19 remain uncharacterized.

Albeit some experimental data suggests a protumorigenic/metastatic function of ADAMTS proteins, particularly in the case of ADAMTS1, the majority of the results indicate that these proteins have a negative effect on tumor progression [7, 8, 24, 25]. Frequent alterations in the expression of these genes have been found in breast cancer, the majority being downregulated (ADAMTS1, ADAMTS3, ADAMTS5, ADAMTS8, ADAMTS9, ADAMTS10, ADAMTS12, and ADAMTS18) but some being upregulated (ADAMTS4, ADAMTS6, and ADAMTS14) [26]. In addition, mutational inactivation, and more frequently, transcriptional silencing by promoter hypermethylation of ADAMTS genes have been found in different types of cancer [8, 27-32]. We recently reported that promoter hypermethylation of ADAMTS14. takes place not only in the tumors but also in the noncancerous colonic mucosa of CRC patients. The methylation of normal colonic mucosa was particularly present in elder African-Americans, suggesting that it is an early event in the carcinogenesis process and a diagnostic marker of a field for cancerization [33]. Nothing is essentially known about the function of ADAMTS19 or its possible role in cancer.

DNA methylation is an epigenetic mechanism with a profound modulating effect on cellular gene expression patterns. Under normal physiological conditions, it plays a crucial role in establishing cell identity during development and cell proliferation. In many human cancers, however, the normal DNA methylation profile is substantially altered. These alterations comprise both abnormal low levels of genome-wide methylation (DNA hypomethylation) and high levels of methylation in other loci (DNA hypermethylation) [34]. Cancer-related DNA hypomethylation mainly occurs in DNA repetitive elements and pericentromeric regions, a phenomenon known to trigger genomic instability [35]. In some cases, DNA hypomethylation has been also found in unique loci leading to transcriptional reactivation [36]. Cancer-related DNA hypermethylation mainly occurs in $\mathrm{CpG}$ islands (CGI) associated with gene promoters and 
is generally accompanied by transcriptional silencing [37]. Since the discovery of the epigenetic inactivation of the tumor suppressor $\mathrm{Rb}$ in the late $80 \mathrm{~s}$ [38], a large number of genes have been found to undergo somatic promoter hypermethylation in human cancer, many of them with tumor suppressor or DNA repair functions [39].

The low or no transcriptional activity of genes with hypermethylated promoter-associated CGI associates with the recruitment of chromatin remodeler complexes that lead to a closed chromatin state [40]. However, after years of intensive research, the primal cause of CGI hypermethylation remains to be defined. The Polycomb (PcGs) and Thritorax (TrxG) group proteins have been suggested to be mechanistically involved in this cancer-specific abnormal hypermethylation, based on the enrichment of PcGs target genes among the genes frequently hypermethylated in cancer [41]. Nevertheless, the reason why some genes may undergo hypermethylation while others do not remains as mysterious today as it was in the over 15-years-old original proposal [42]. The strong association of methylation with mutations in BRAF in CRC [43] and isocitrate dehydrogenase 1 gene (IDH1) in gliomas [44] provides interesting clues but as indirect pleiotropic effects, rather than direct mechanistic causal relationships.

In this report, we characterized the promoter region of ADAMTS19 frequently hypermethylated in CRC [45] and extended this observation to other cancers. We correlated methylation with cancer genotype and with clinicopathological parameters, especially the metastatic homing preference. We also studied in vitro the effect of ADAMTS19 transcriptional silencing in CRC phenotype.

\section{Results}

\section{Hypermethylation of ADAMTS19 5' CpG island in gastrointestinal primary tumors}

This study spawns from a previous work where we analyzed methylation alterations in colorectal and gastric cancers by methylation-sensitive amplification length polymorphism (MS-AFLP). This is a DNA fingerprinting technique based on the methylation-sensitive cleavage of NotI, a restriction endonuclease that contains in its recognition sequence two CpG dinucleotides [45]. A MS-AFLP band named C-19 was the most frequent hypermethylated in both gastric $(38 / 89,42.7 \%)$ and colorectal $(25 / 73,34.2 \%)$ cancers [45]. The C-19 band was mapped (see Methods) to the 5' region of the ADAMTS19 gene (Fig. 1a).

We confirmed that methylation alterations of the ADAMTS19 CGI were responsible for the changes in intensity of band C-19 (Additional file 1: Figure S1) [46]. We also analyzed the association between hypermethylation identified by MS-AFLP (which is reflected by weaker intensity of the fingerprint bands) and copy number changes. ADAMTS19 is located in chromosome 5q, $16.8 \mathrm{Mb}$ telomeric to tumor suppressor $A P C$, frequently lost in CRC. Over 50 cases were analyzed for loss of heterozygosity $(\mathrm{LOH})$ and copy number changes in $5 \mathrm{q}$ by microallelotyping and array comparative genomic hybridization (CGH) (Additional file 1: Figure S2). There was no association between copy number alterations and the MS-AFLP scoring, showing that band C-19 changes reflected methylation alterations rather than genomic loss of ADAMTS19.

We studied the extent of hypermethylation of ADAMTS19 in 15 CRCs by bisulfite sequencing [47, 48]. The results confirmed that hypermethylation of ADAMTS19 was exclusive of the tumor tissues and extended throughout the gene promoter region (Fig. 1b). Thus, we used combined bisulfite and restriction analysis (COBRA), a simpler and less expensive method (Fig. 1c), to complete the analysis of 42 colonic adenomas, 210 primary CRCs, 70 metastases (Table 1), and their corresponding normal tissues (for every patient, we analyzed both the tumor and the colonic normal mucosa). ADAMTS19 was hypermethylated in $48 \%$ of adenomas, $35 \%$ of adenocarcinomas, and $31 \%$ of metastases but never in the 322 normal tissues corresponding to the tumoral samples.

\section{ADAMTS19 hypermethylation is independent of hypermethylation of surrounding $\mathrm{CpG}$ islands}

We studied the methylation of the chr5 123.8-133.8 Mb ADAMTS19 region in $35 \mathrm{CRCs}$ and their matching normal tissues using Illumina HM450K methylation arrays. The concordance between the COBRA scoring and the Illumina HM450K arrays data was $100 \%$. Within the $3.5 \mathrm{Mb}$ chromosomal region around ADAMTS19, there are ten CGI (Fig. 2). The genes fibrillin 2 (FBN2) and SLC27A6 (a fatty acid transporter) CGIs, located 0.9 and $0.5 \mathrm{Mb}$ upstream of ADAMTS19, respectively, were concomitantly hypermethylated. chondroitin sulfate synthase 3 (CHSY3) located $0.45 \mathrm{Mb}$ downstream of ADAMTS19 was also hypermethylated in some tumors. There was no correlation between methylation of ADAMTS19 CGI and methylation of any of these three genes (Fig. 2), indicating that ADAMTS19 hypermethylation was an independent event and not a secondary effect of hypermethylation in the neighboring chromosomal region.

\section{ADAMTS19 hypermethylation and clinicopathological and molecular parameters in CRC}

ADAMTS19 methylation in primary CRC did not associate with gender, race, age, or tumor location (Fig. 3a and Additional file 1: Figure S3). We found, however, a positive association with MSI status (odds ratio $(\mathrm{OR})=2.7$, confidence interval $(\mathrm{CI})=(1-7.3), p=0.035)$ and with $B R A F$ mutations $\left(\mathrm{OR}=10, \mathrm{CI}=(3.1-42.9), p=6.3 \times 10^{-6}\right)$ (Fig. 3b). In a multivariate logistic regression analysis including MSI and BRAF as factors, the association with $B R A F$ mutation retained statistical significance 


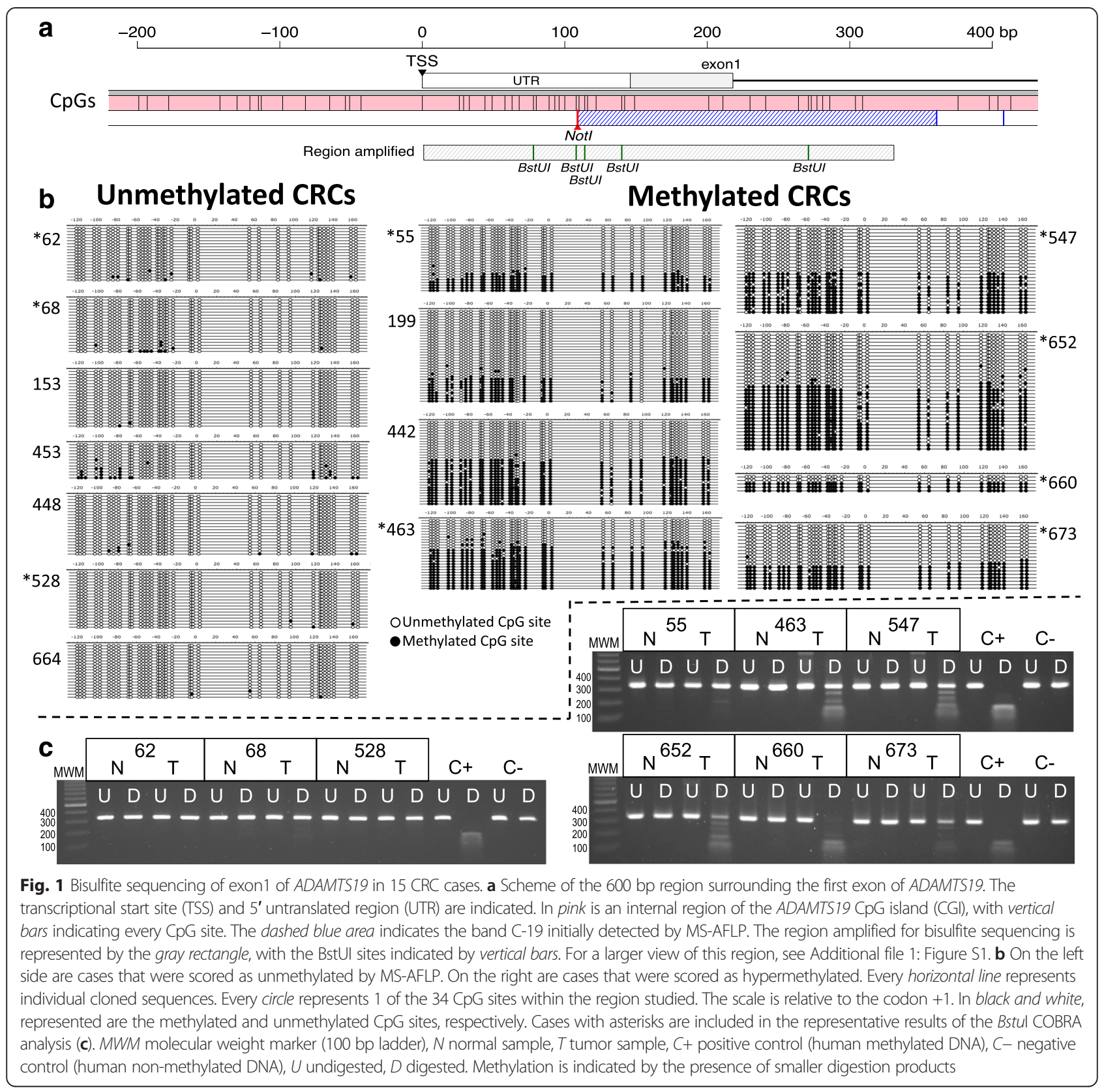

$\left(\mathrm{OR}=10.5, \mathrm{CI}=(3.3-43.2), p=2.7 \times 10^{-4}\right)$ while the association with MSI status did not $(\mathrm{OR}=0.94, \mathrm{CI}=(0.27-$ 2.83), $p=0.91$ ).

\section{ADAMTS19 hypermethylation profile in gastrointestinal and gynecological cancers}

To investigate whether ADAMTS19 hypermethylation was exclusive of gastric and colorectal cancers, we analyzed 356 primary tumor samples from other malignancies. ADAMTS19 hypermethylation was more frequent in cancers of gastrointestinal origin (stomach, colon, and pancreas) than ovarian and breast cancers $(\mathrm{OR}=2.9$, $\mathrm{CI}=(1.9-4.7), p=5.2 \times 10^{-7}$, Fig. 4a) .
Analysis of the methylation data from the Cancer Genome Atlas (TCGA) validated our findings (Fig. 4b). In the TCGA datasets ADAMTS19 was frequently hypermethylated in gastrointestinal cancers including stomach (47.6$53.7 \%)$, esophageal (39.8\%), liver (30.9\%), colorectal (22.2-25.2 \%), and pancreatic cancers (13.8\%). In contrast, methylation incidence was much lower in breast (1.5-2.5\%), ovarian (1\%), or prostate (0.5\%) cancers. The TCGA data also confirmed the strong association between ADAMTS19 hypermethylation and BRAF mutations in 220 CRCs $\left(\mathrm{OR}=30.2, \mathrm{CI}=(8.3-167), p=4.4 \times 10^{-11}\right)$.

ADAMTS19 hypermethylation associated with the mucinous phenotype in primary CRCs $(\mathrm{OR}=2.1, \mathrm{CI}=(1.1-4.2)$, 
Table 1 Demographics and clinical characteristics of the patients and samples analyzed in this study

\begin{tabular}{|c|c|c|c|c|}
\hline \multirow[b]{2}{*}{ Number } & \multirow{2}{*}{$\begin{array}{l}\text { Adenomas } \\
42\end{array}$} & \multirow{2}{*}{$\begin{array}{l}\text { Carcinomas } \\
210\end{array}$} & \multirow{2}{*}{$\begin{array}{l}\text { Metastases } \\
70\end{array}$} & \multirow{2}{*}{$\begin{array}{l}\text { Carcinomas vs. } \\
\text { Metastases }\end{array}$} \\
\hline & & & & \\
\hline Age & $n=42$ & $n=210$ & $n=66$ & \\
\hline Mean \pm SD & $64.2 \pm 11.4$ & $65.1 \pm 14.1$ & $62.5 \pm 11.5$ & $p=0.12$ \\
\hline Range & $30-80$ & $18-93$ & $33-86$ & \\
\hline Gender & $n=42$ & $n=210$ & $n=66$ & \\
\hline Female & $13(31 \%)$ & $98(47 \%)$ & $28(40 \%)$ & \\
\hline Male & $29(69 \%)$ & $112(53 \%)$ & $38(54 \%)$ & $p=0.57$ \\
\hline Information not available & & & $4(6 \%)$ & \\
\hline Race & $n=27$ & $n=161$ & $n=63$ & \\
\hline Caucasian & $18(43 \%)$ & $125(60 \%)$ & $57(81 \%)$ & \\
\hline African-American & $9(21 \%)$ & $36(17 \%)$ & $6(9 \%)$ & $p=0.035$ \\
\hline Other/not well defined & 15 (36 \%) & $49(23 \%)$ & $7(10 \%)$ & \\
\hline Location $^{a}$ & $n=40$ & $n=210$ & $n=32$ & \\
\hline Proximal & $27(64 \%)$ & 110 (52 \%) & $9(13 \%)$ & \\
\hline Distal & $13(31 \%)$ & 100 (48 \%) & $23(33 \%)$ & $p=0.013$ \\
\hline Information not available & $2(5 \%)$ & 0 & 38 (54 \%) & \\
\hline Stage (Dukes') & & $n=210$ & & \\
\hline A & NA & $18(9 \%)$ & NA & \\
\hline B & NA & 77 (37 \%) & NA & \\
\hline C & NA & $59(28 \%)$ & NA & \\
\hline D & NA & $56(27 \%)$ & NA & \\
\hline Grade & & $n=202$ & $n=32$ & \\
\hline Well/moderate & NA & 156 (74 \%) & $32(46 \%)$ & \\
\hline Poor & NA & $46(22 \%)$ & $2(3 \%)$ & $p=0.021$ \\
\hline Information not available & NA & $8(4 \%)$ & $36(51 \%)$ & \\
\hline Mucinous phenotype & & $n=210$ & $n=70$ & \\
\hline Non-mucinous & & 151 (72 \%) & 57 (81\%) & \\
\hline Mucinous & & $59(28 \%)$ & $13(19 \%)$ & $p=0.15$ \\
\hline MSI & $n=41$ & $n=208$ & $n=62$ & \\
\hline MSS & $40(95 \%)$ & $185(88$ \%) & $62(89 \%)$ & \\
\hline MSI & $1(2 \%)$ & $23(11 \%)$ & 0 & $p=0.003$ \\
\hline Information not available & $1(2 \%)$ & $2(1 \%)$ & $8(11 \%)$ & \\
\hline TP53 & $n=33$ & $n=191$ & $n=42$ & \\
\hline WT & $28(67 \%)$ & $104(50 \%)$ & $18(26 \%)$ & \\
\hline MUT & $5(12 \%)$ & $87(41 \%)$ & 24 (34 \%) & $p=0.23$ \\
\hline Information not available & $9(21 \%)$ & 19 (9 \%) & $28(40 \%)$ & \\
\hline KRAS & $n=42$ & $n=195$ & $n=50$ & \\
\hline WT & 19 (45 \%) & $117(56 \%)$ & $32(46 \%)$ & \\
\hline MUT & $23(55 \%)$ & $78(37 \%)$ & $18(26 \%)$ & $p=0.63$ \\
\hline Information not available & 0 & $15(7 \%)$ & $20(29 \%)$ & \\
\hline BRAF & $n=12$ & $n=175$ & $n=34$ & \\
\hline WT & $12(29 \%)$ & $153(73 \%)$ & 32 (46 \%) & \\
\hline
\end{tabular}


Table 1 Demographics and clinical characteristics of the patients and samples analyzed in this study (Continued)

\begin{tabular}{llll}
\hline MUT & 0 & $22(10 \%)$ & $2(3 \%)$ \\
Information not available & $30(71 \%)$ & $35(17 \%)$ & $36(51 \%)$ \\
\hline
\end{tabular}

For every parameter, the number of cases with information is indicated $(\mathrm{n}=)$

NA not applicable

a In the metastases column, location refers to the originating primary lesion when known

$P$ values of the comparison between carcinomas and metastases were obtained by Fisher's test except for Age, where Student's $t$ test was applied

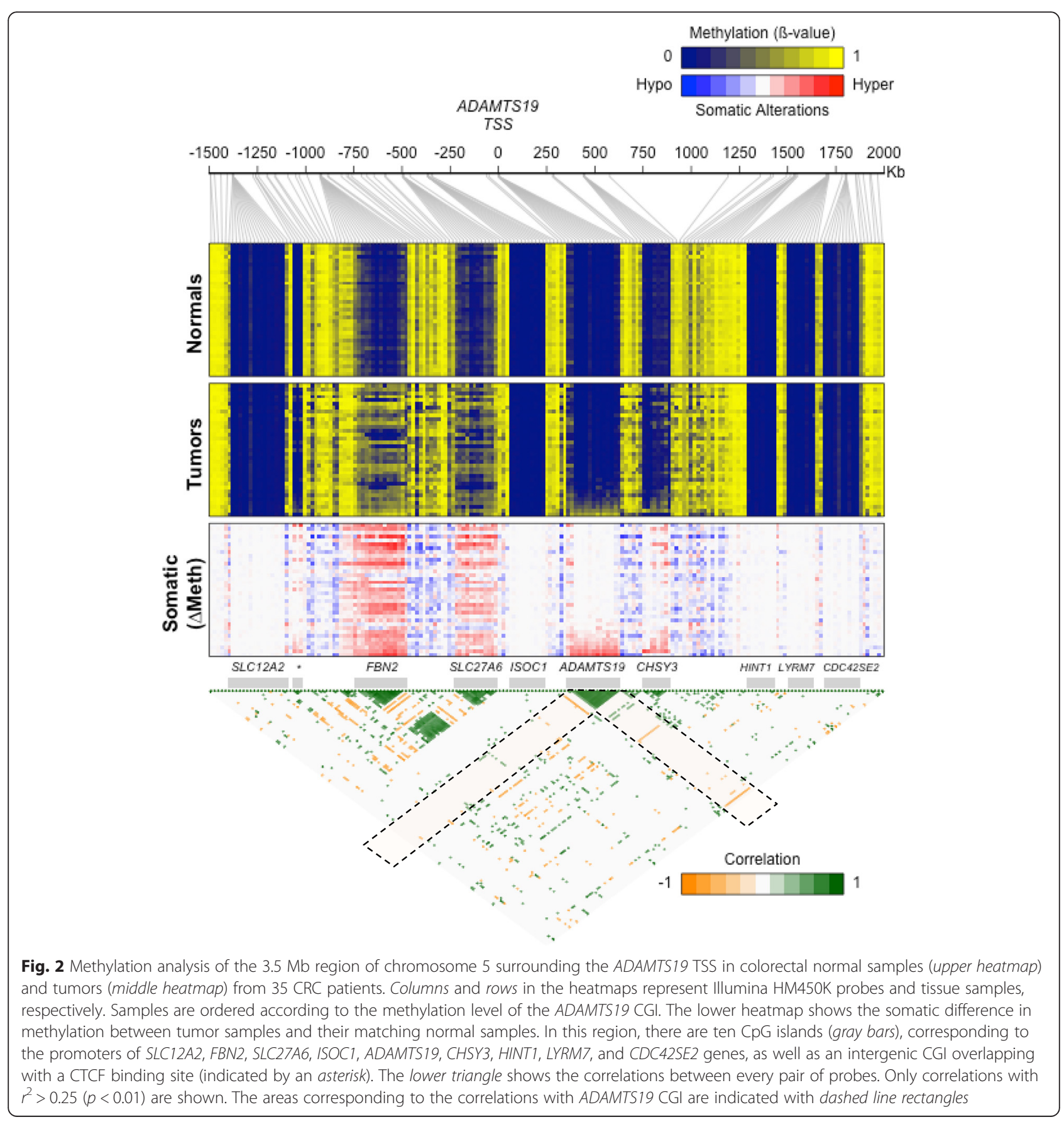



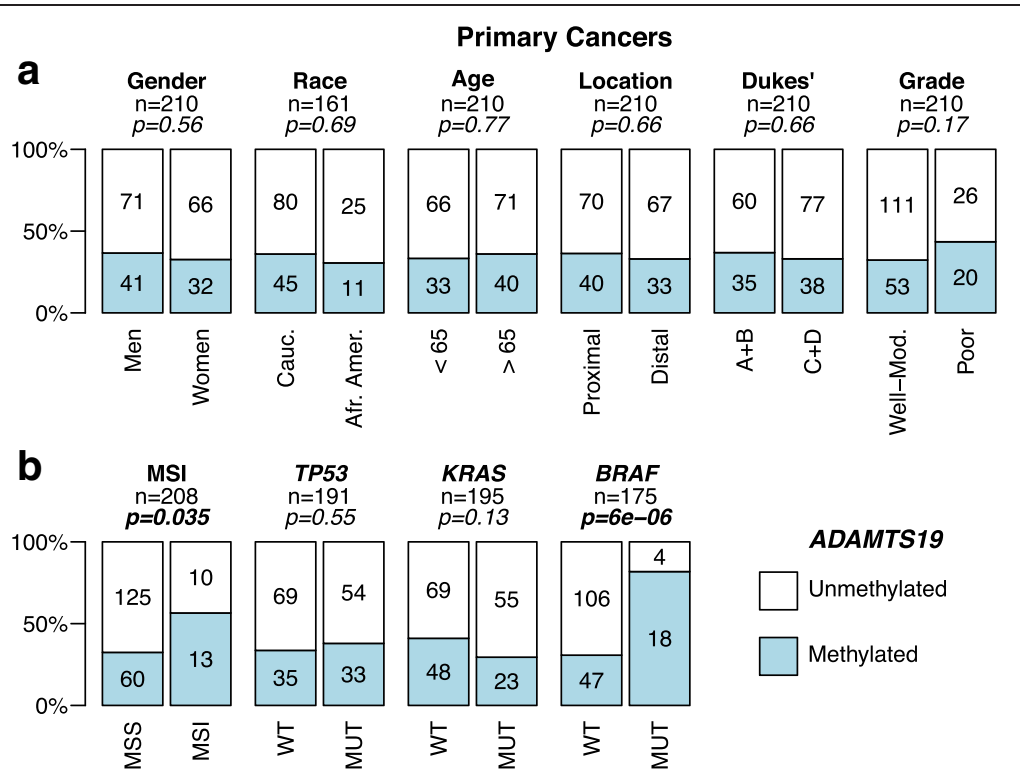

Fig. 3 ADAMTS19 hypermethylation and CRC clinicopathological characteristics (a) and tumor genotype (b). Tumor stage is indicated using the Dukes' classification, grouping A and B vs. C and D. WT wild type, MUT mutated. P values were calculated by Fisher's exact test

$p=0.023)$. A much stronger association was observed in ovarian cancers $(\mathrm{OR}=60, \mathrm{CI}=(16-346), p=3.9 \times$ $\left.10^{-16}\right)$. None of the serous or endometrioid type tumors, which are the most frequent types of ovarian cancer, exhibited ADAMTS19 hypermethylation (Fig. 4c). The only other three methylated cases in the nonmucinous subgroup of ovarian cancer were clear-cell tumors.

\section{ADAMTS19 methylation associates with local, but not with distant, CRC metastases}

ADAMTS19 hypermethylation was frequent in adenomas and showed a trend for decreasing frequency during tumor progression (Fig. 5a). ADAMTS19 methylation was significantly higher in local metastases to the omentum and ovary than to distant organs, the liver and lung $(\mathrm{OR}=$ $6.1, \mathrm{CI}=(1.8-22.2), p=0.0017$, Fig. 5b). By differentiating

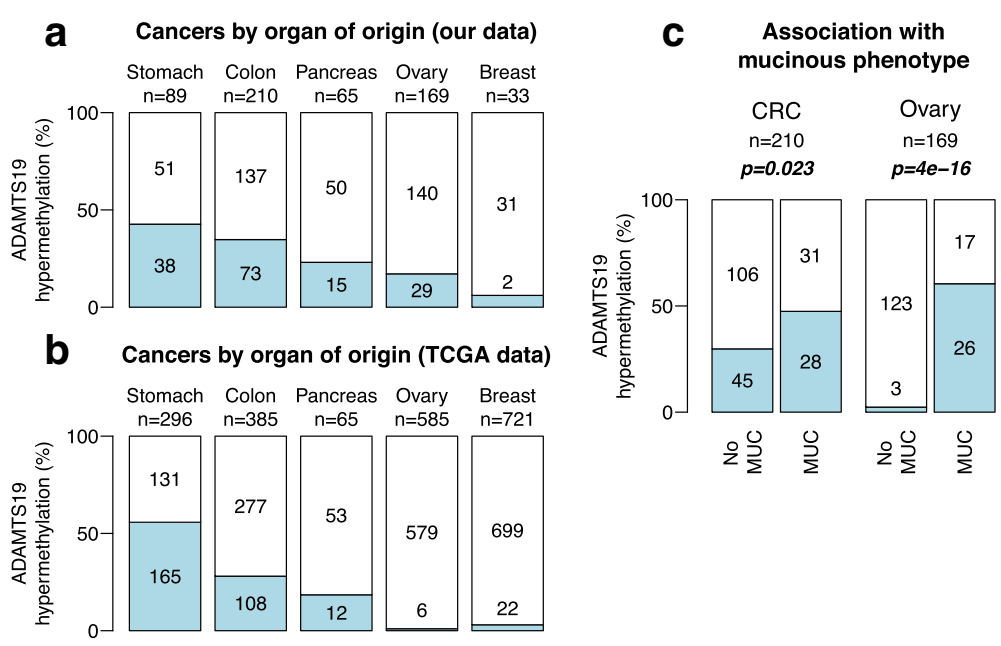

Fig. 4 ADAMTS19 hypermethylation incidence in primary tumors of different origins in tumors from our collection (a) and from the TCGA datasets (b). In blue are ADAMTS19 hypermethylated cases. A higher incidence is found in gastrointestinal cancers compared to ovary and breast cancers $\left(p=5.2 \times 10^{-7}, \mathrm{OR}=2.9, \mathrm{Cl}=(1.9-4.7)\right.$, Fisher's exact test). $\mathbf{c}$ ADAMTS19 hypermethylation associates with mucinous phenotype in CRC and ovarian cancers ( $p=0.023$ and $p=4 \times 10^{-16}$, respectively, Fisher's exact test). The three ovarian cancer cases with ADAMTS19 hypermethylation in the no mucinous group were the only three clear-cell adenocarcinomas 


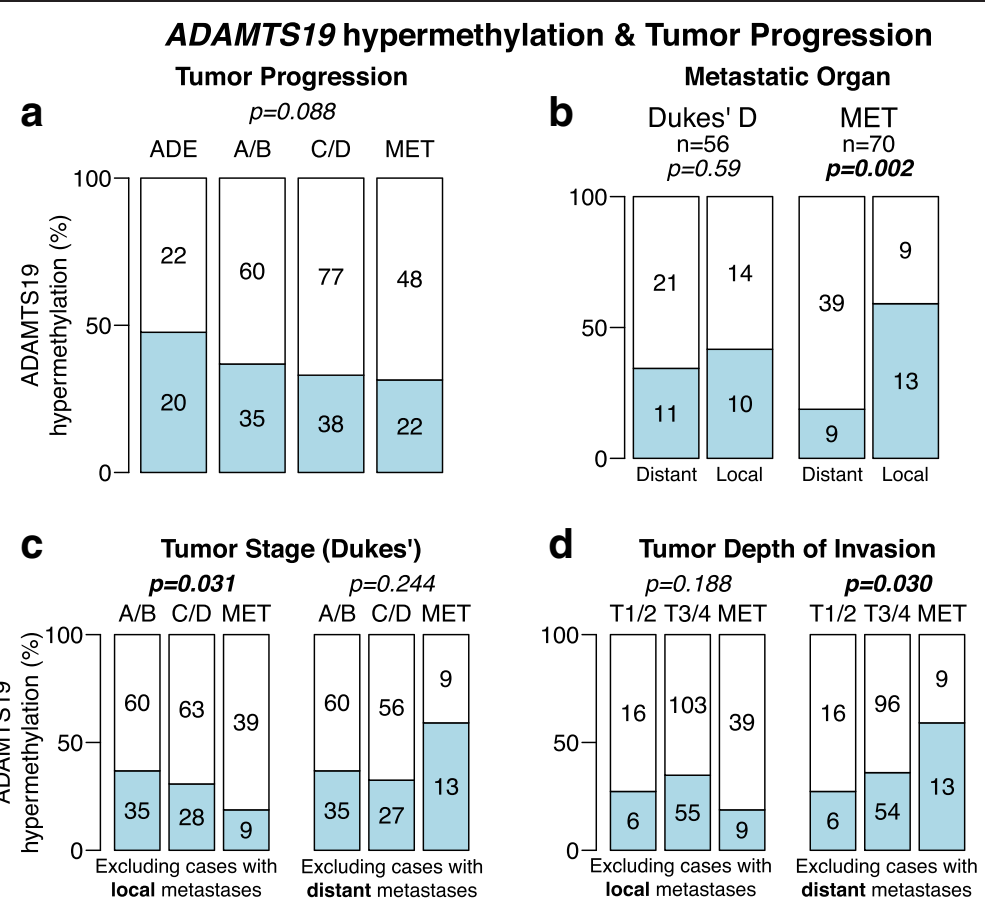

Fig. 5 ADAMTS19 hypermethylation and CRC tumor progression and invasion. a Incidence of ADAMTS19 hypermethylation in adenomas (ADE), primary CRCs (grouping Dukes' A $+B$ and $C+D$ ), and metastases (MET). $\mathbf{b}$ Incidence of ADAMTS19 hypermethylation in Dukes' D primary cancers that metastasized to distant (mostly the liver or lung) or to local (mostly the ovary or omentum) organs and in metastases (MET). $\mathbf{c}$ Incidence of ADAMTS19 methylation vs CRC progression in primary cancers (Dukes' scale, grouping A/B and C/D). $\mathbf{d}$ Incidence of ADAMTS19 methylation and depth of invasion in primary cancers (TNM scale, grouping T1/2 and T3/4). $P$ values were calculated by Fisher's exact test (b) and by Cochran-Armitage test for trends (a, $\mathbf{c}$, and $\mathbf{d})$

between distal and local metastases, inverse trends became significant. Thus, methylation decreased from nonmetastatic CRCs (Dukes' A + B) to metastatic CRCs (Dukes' C $+\mathrm{D}$ ) to metastases to the liver and lung ( $p=$ 0.031, Cochran-Armitage test) (Fig. 5c). Inversely, association with the depth of invasion revealed an increased incidence of methylation in more invasive tumors and their corresponding local metastases $(p=0.030$, CochranArmitage test) (Fig. 5d).

\section{Methylation associates with gene silencing and demethylation restores ADAMTS19 expression} Genomic DNA from Colo205, DLD1, HCT8, HCT15, HCT116, HT29, LoVo, LS180, SW48, and SW480 CRC cell lines was treated with bisulfite, polymerase chain reaction (PCR) amplified, and cloned. Five plasmid clones from each cell line were isolated and sequenced. The results revealed different methylation patterns with some of the cell lines heavily methylated, while others were essentially unmethylated (Additional file 1: Figure S4). The expression level of ADAMTS19 in these cell lines was analyzed by quantitative reverse transcription polymerase chain reaction (RT-PCR). Cell lines with full methylation of ADAMTS19 CGI did not exhibit detectable levels of expression. Some of the cell lines with intermediate levels of methylation expressed the gene at very low level, but the highest level of expression corresponded to the fully demethylated cell lines DLD1/HCT15 and SW480 (Additional file 1: Figure S4). We studied the association between methylation and transcriptional levels by treating these cell lines with the demethylating agent 5-AZA-2-deoxycytosine (AdC). After $48 \mathrm{~h}$ of treatment, ADAMTS19 expression was analyzed by RT-PCR. The results confirmed that pharmacological demethylation with AdC restored expression in the four fully methylated cell lines (HT29, SW48, Colo205, and HCT116) (Additional file 1: Figure S4).

\section{ADAMTS19 downregulation reduces the migration capabilities of CRC cells}

To investigate the phenotypic effect of ADAMTS19 silencing, we performed knockdown experiments with interference RNA (shRNA) in DLD1 and SW480 cell lines, having no methylation and exhibiting the highest levels of expression (Additional file 1: Figure S4b). We designed three different specific shRNAs targeting exons 3,13 , and 22 (shA19e3, shA19e13, and shA19e22, respectively). These shRNAs were transfected into SW480 and DLD1 separately and in different combinations. As negative controls, cells were transfected with vectors 
containing shRNA targeting luciferase (shLuc) or GFP (shGFP1 and shGFP2) genes, both absent in these cells. Transfected cells were selected by culture with puromycin. ADAMTS19 transcriptional levels were analyzed by RT-PCR to determine the efficiency of these shRNAs in stably transfected cells. The most efficient silencing was achieved with shA19e22, which downregulated the levels of expression of ADAMTS19 to less than $30 \%$ of untreated levels in SW480 (Additional file 1: Figure S5). Similar results were obtained in DLD1. To investigate whether some subclones achieved even stronger downregulation, 10 subclones of the shA19e22 transfected SW480 cells were isolated and individually evaluated for ADAMTS19 expression. These subclones exhibited little deviation from the silencing level measured in the cell pool (Additional file 1: Figure S5).

ADAMTS19 silencing did not affect the in vitro growth rate or anchorage-free growth capabilities (Additional file 1: Figure S6) of ADAMTS19-downregulated SW480 cells. We also studied changes in invasion potential in vitro by Matrigel-coated Transwell assays. However, the only parental cell lines with high expression of ADAMTS19 (DLD1/HCT15 and SW480) exhibited very low capability to migrate through the Matrigel layer (averaging 1 or 2 cells per view field), yielding no statistically significant observable difference between the cells with and without knockdown of gene expression (not shown). However, we found a significant reduction in the migratory capabilities of SW480 cells upon ADAMTS19 downregulation, measured by two complementary methods, i.e., wound healing (Additional file 1: Figure S7) and collagen I coated Transwell assays (Fig. 6).

\section{Discussion}

We were intrigued by the observation that ADAMTS19 hypermethylation was the most common epigenetic alteration observed in gastric and colorectal cancers among the many loci analyzed by unbiased MS-AFLP fingerprinting. The rationale to investigate this finding in more depth seemed justified because of the established role of ADAMTS proteins in tumorigenesis, and at the same time, the unexplored nature of the ADAMTS19 in the process. Once the fingerprinting observation was validated by direct bisulfite sequencing and other complementary epigenomic techniques, we explored in a descriptive study the involvement of this somatic epigenetic alteration in several malignancies. The results showed a specific association with gastrointestinal cancers that was corroborated by in silico analysis of the public TCGA data. Methylation also associated with silencing and demethylation in vitro by azacytidine restored expression.

We then correlated the methylation alterations with clinicopathological and genetic parameters in CRC. No significant associations were found with any of the

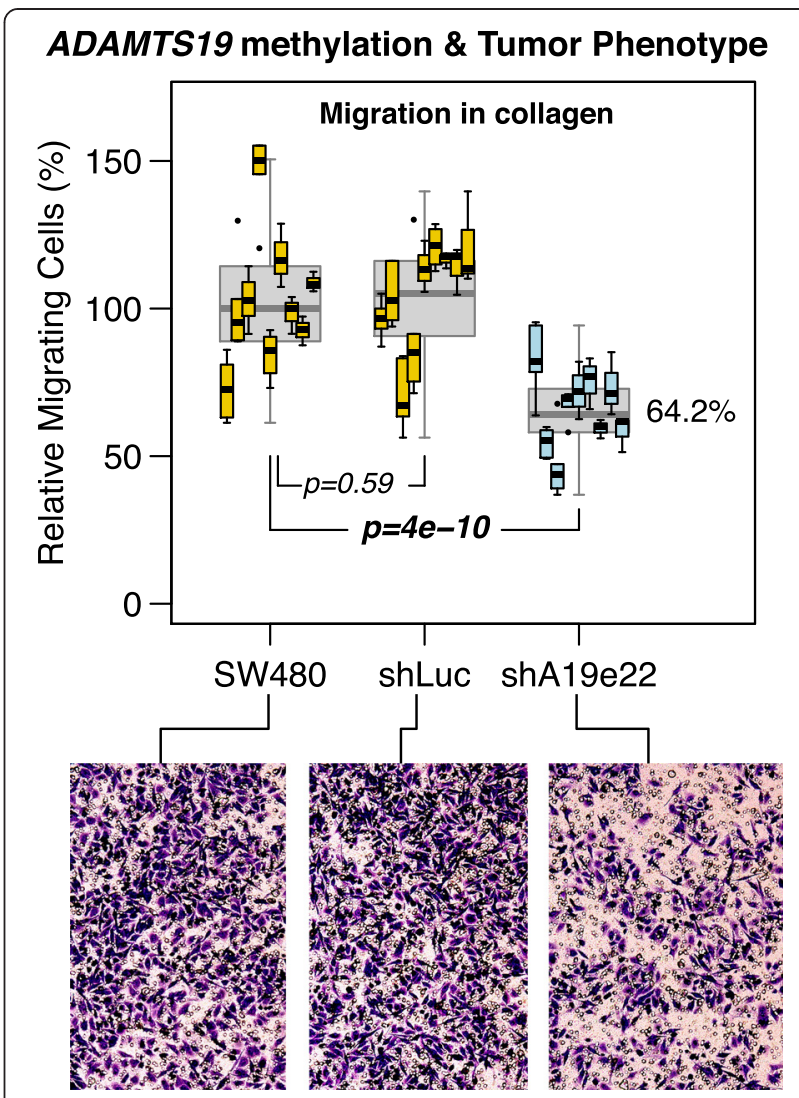

Fig. 6 Silencing of ADAMTS19 with shA19e22 reduces the migration capabilities of SW480 cells. Transwell migration assay using a matrix of collagen I. Experiments were performed in three independent replicates, using three wells per cell line in each replicate, and examining three to six microscope fields per well. No statistically significant difference was detected between replicates. In gray are boxplots combining all the values per cell line. In orange are boxplots showing the values of individual wells in controls (SW480 and SW480 transfected with shLuc) and in blue the ADAMTS19silenced cell line SW480 transfected with shA19e22. A $35.8 \%$ reduction of median migratory capabilities was observed in SW480 cells transfected with shA19e22. P values were calculated by Tukey's honest significance method on a nested ANOVA model

demographic, pathological, or genetic data analyzed except with the MSI status and mutations in BRAF (most of them MSI cancers, Fig. 2). This is consistent with previous observations showing that BRAF-mutant CRCs exhibit a higher frequency of somatic CGI hypermethylation.

When analyzed in relation to metastatic spread, methylation showed a much lower association with metastases homing to distant (i.e., the lung and liver) organs in comparison with those metastases to local organs such as the ovary and omentum. Finally, in an effort to find a connection genotype-phenotype, we studied several cellular phenotypes related to cell growth and migration. The results overall are not conclusive, and the putative role in CRC pathogenesis of the epigenetic silencing of ADAMTS19 remains to be established. However, we have several clues 
that point to an active contributory role in CRC tumor progression.

First, the tumor-specific somatic hypermethylation does not appear to be a random and general epiphenomenon because it is restricted to gastrointestinal malignancies, as it is essentially absent in ovarian and breast cancers. Moreover, methylation associates with the manifestation of the mucinous phenotype in CRC and especially in ovarian cancer. The striking association between ADAMTS19 methylation and the mucinous phenotype in ovarian cancers, a subtype of cancer of difficult diagnosis due to its resemblance to secondary lesions of colorectal origin, opens a number of avenues for further investigation with potential diagnostic applications.

Second, methylation is not consequence of a local epigenetic disturbance in the genome driven by a nearby "culprit" gene. This conclusion is supported by the discontinuous map of hypermethylation in the ADAMTS19 region and the absence of association between methylation of ADAMTS19 and any of the adjacent genes, some of which are indeed methylated in CRC even with higher frequency (Fig. 2). In particular, FBN2, is an obvious candidate for the targeted hypermethylation of this chromosomal region because mutations in the gene have been linked to Marfan-like syndromes [49] and because hypermethylation has been reported as a biomarker in CRC and other cancers [50-52]. However, notwithstanding a putative independent role of $F B N 2$ in CRC, we conclude that $F B N 2$ is not the main target for inactivation because of the following considerations: Methylation of this gene is not specific for tumor cells as it shows some weaker methylation in normal tissue, which is not the case for ADAMTS19 (Fig. 2). Moreover, FBN2 is not included in the microdeletion of this chromosomal region present in one of the CRCs analyzed by array CGH that targets only the ADAMTS19 gene and the very few adjacent genes. The result is conclusive because a polymorphic CA repeat located outside the $F B N 2$ gene retained heterozygosity in this tumor, showing that FBN2 was not affected by the microdeletion (Additional file 1: Figure S2). This microdeletion also adds evidence for the existence of a selective pressure for the loss of ADAMTS19 in the early stages of CRC.

In contrast with the absence of association between hypermethylation of FBN2 and ADAMTS19, there is a coordinated hypermethylation of this metallopeptidase and other members of the ADAMTS gene family that extends across the genome (data not shown). The mechanism underlying this intriguing trans-acting positive correlation in ADAMTS methylation is inexplicable at the moment and deserves further analysis. Nevertheless, it also serves as a comparative control over the lack of correlation with the genes adjacent to ADAMTS19, showing that the gene is a target in itself for somatic hypermethylation in a subset of CRC.
Third, the most direct evidence for a functional role of ADAMTS19 hypermethylation is the observed phenotypic changes after downregulation of its expression. This proves that silencing is not inconsequential. However, there is no sufficient data to provide a clear picture of the actual role of ADAMTS19 and its epigenetic alteration in CRC tumorigenesis because of the complex features so far emerging of its involvement. Silencing and downregulation accompanied by inhibition of migration is not easily reconciled with a functional role in tumor progression. However, the asymmetries observed in the incidence of methylation during tumor progression and metastatic spread may indeed provide some potential explanations. A positive selection for cells with a methylated and silenced gene during the early stages of CRC development may be followed by a reverse selection in more advanced stages of tumor invasion and progression. This also is to be understood in the context of the different behavior of the epigenetic alterations depending on the different parameters ruling tumor progression: There appears to be a negative association with stage of progression but a positive association with the depth of invasion (Fig. 5). Similarly, there is a decreased of incidence in methylation in distant hepatic and lung metastases but an increased incidence of local metastases such as the ovary and omentum (Fig. 5).

ADAMTS19 hypermethylation frequency was higher in adenomas $(47.6 \%)$ than in carcinomas $(34.6 \%)$ or metastases $(30.9 \%)$. Considering MSS tumors only, the results were essentially the same, $50 \%$ in adenomas, $32.4 \%$ in adenocarcinomas, and $29.5 \%$ in metastases, revealing an asymmetry between premalignant and malignant tumors $(\mathrm{OR}=0.47, \mathrm{CI}=(0.22-0.97), p=0.031)$. This suggests that ADAMTS19 hypermethylation could be detrimental for tumor progression, i.e., adenomas with ADAMTS19 hypermethylation would be less likely to become malignant or carcinomas less metastatic. However, our data is the endpoint analysis of different samples and does not necessarily represent an accurate time-course of the adenoma-carcinoma-metastasis progression. The cases with primary-metastases from the same CRC patients were too few to reach meaningful conclusions in this regard, but to increase the sample size of these cases is an obvious course of action in the future.

The main difficulty in proposing a coherent model for the role of ADAMTS19 hypermethylation in CRC resides in the generally accepted irreversibility of aberrant hypermethylation. Why a gene that undergoes hypermethylation early on during tumorigenesis would have a drop in methylation incidence later on the process is not altogether clear. For the reasons discussed before, the first "passenger" hypothesis to explain methylation as inconsequential seems unlikely. The simplest explanation 
for a functional role of hypermethylation is that the primary tumor may be heterogeneous for methylation status, with the cells that eventually disseminate and colonize the liver, for instance, coexisting unmethylated in the primary tumor with other methylated sister cells. In support of this hypothesis, some of the clones from ADAMTS19 methylation-positive tumor samples analyzed by bisulfite sequencing (Fig. 1b) were essentially unmethylated, resembling the methylation pattern of the normal tissue. The most likely explanation is that ADAMTS19 methylation is heterogeneous in the cell population. In addition to contamination with normal cells (obligated in primary tumor samples), non-clonal methylation may account for this heterogeneity.

Our in vitro studies indicate that ADAMTS19 downregulation reduces the motility of cancer cells (Fig. 6 and Additional file 1: Figure S7), suggesting that ADAMTS19 hypermethylated cells could be less capable to escape the tumor mass and migrate to distant organs through the vascular system. This effect was observed despite the fact that shRNA-induced downregulation did not completely silence ADAMTS19 transcription. The analysis of mRNA expression in cell lines (Additional file 1: Figure S4) suggests that promoter hypermethylation has a stronger downregulation effect. Therefore, it is possible that in vivo ADAMTS19 hypermethylation exerts a stronger negative effect on the migration capabilities of tumor cells. This hypothesis predicts that some of the clonally methylated tumors will generate methylated metastases, preferentially to local organs (the ovary or omentum), while other tumors non-clonal for methylation will generate unmethylated metastases preferentially to distant organs (the liver or lung). While metastatic spread to distant organs involves intraand extravasation, the dissemination into the peritoneal cavity may occur by direct spread of floating tumor cells once the primary tumor invades and penetrates through the colon wall. Inhibition of migration would not hamper the metastatic dissemination in this context. This is most likely an over-simplifying hypothesis but at least provides a working model for the differences in metastatic homing by the cells with and without ADAMTS methylation.

\section{Conclusions}

In summary, our results demonstrate that the promoter of ADAMTS19 is targeted by hypermethylation in a significant proportion of gastrointestinal cancers, particularly in $B R A F$-mutant cancers, and that this hypermethylation associates with transcriptional downregulation and reduces the in vitro migration capabilities of CRC cells. The link between methylation of this gene and altered in vivo migration and invasion capabilities of metastatic cells remains to be established. A more detailed study with animal model systems for metastasis of CRC seems an obvious approach. All together, our findings reinforce the emerging role of extracellular matrix homeostasis disruption as a relevant event in cancer progression in general and CRC in particular $[8,53,54]$.

\section{Methods}

\section{Cell lines and human tissues}

Freshly frozen human cancers and normal matching tissues (from each one of the patients) were obtained from the Cooperative Human Tissue Network [55]. Colon cancer cell lines Colo205, DLD1, HCT8, HCT15, HCT116, HT29, LoVo, LS180, SW48, and SW480 were obtained from the American Type Culture Collection, Rockville, MD, USA. Cell lines were authenticated by STR profiling using Identifiler Plus PCR Amplification kit (Life Technologies). DLD1 and HCT15 cell lines are in fact the same, as they were derived from the same tumor, although due to their mutator phenotype they harbor several genotypic differences [56]. SanfordBurnham Institutional Review Board approved the research protocol, which was in compliance with national legislation and performed according to the ethical guidelines of the Declaration of Helsinki [57].

\section{Cell culture conditions}

Cells were cultured in DMEM-F12 (Life Technologies) supplemented with fetal bovine serum $10 \%(v / v)$, antibiotics, and antimycotics on $100 \mathrm{~mm}$ culture dishes in a $37^{\circ} \mathrm{C}$ incubator with $5 \% \mathrm{CO}_{2}$. Unless otherwise indicated, cells were grown until reaching 80-90\% confluency before collection. When needed, 5-aza-2'-doexycytidine (5AdC) was added to the culture media at a final concentration of $1 \mu \mathrm{M}$.

\section{DNA methylation analyses}

MS-AFLP was performed as previously described, using primer NotI $+G$ in three separate combinations with primers MseI + CA, MseI + CG, and MseI + C $[45,58]$. We used a SacII-based quantitative analysis for methylation, a method similar to MethylScreen [46], with some modifications. Briefly, genomic DNA was first sheared by digestion with EcoRI at $37{ }^{\circ} \mathrm{C}$ during $2 \mathrm{~h}$. Then the sample was divided into two aliquots. One of them was treated with the methylation-sensitive enzyme SacII at $37{ }^{\circ} \mathrm{C}$ for $4 \mathrm{~h}$, while the other was subjected to the same incubation but in the absence of restriction enzyme. Then, the percentage of methylated molecules was estimated as the proportion of DNA molecules resistant to digestion in the SacII-treated aliquot, evaluated by quantitative PCR in a LightCycler 480 System (Roche), with primers P28 and P29 (see Additional file 1: Table S1), and using the SacII-untreated aliquot as reference. For bisulfite sequencing $[47,48]$ and combined bisulfite and restriction analysis (COBRA) [59], $1 \mu \mathrm{g}$ of genomic DNA was treated with bisulfite (EZ-methylation kit, Zymo Research). Human methylated and non-methylated DNA standards 
(Zymo Research) were used as controls. After bisulfite treatment, the promoter region of ADAMTS19 was amplified by a two-step nested PCR. Conditions for the first amplification step were $100 \mathrm{ng}$ of bisulfite-treated DNA as template, primers $\mathrm{P} 44$ and $\mathrm{P} 46$ at a final concentration of $0.4 \mu \mathrm{M}$ each, dNTPs at $0.125 \mu \mathrm{M}$ each, Q-Solution 0.5X, and one unit of Hotstart DNA Polymerase (Qiagen) in a total volume of $20 \mu \mathrm{L}$. The PCR program consisted of 1 cycle at $95{ }^{\circ} \mathrm{C}$ for $5 \mathrm{~min}$ to activate the enzyme, followed by 35 cycles of denaturation at $95{ }^{\circ} \mathrm{C}$ for $5 \mathrm{~s}$, annealing at $55^{\circ} \mathrm{C}$ for $30 \mathrm{~s}$, and extension at $72{ }^{\circ} \mathrm{C}$ for $60 \mathrm{~s}$, ending at $72{ }^{\circ} \mathrm{C}$ for $5 \mathrm{~min}$ to complete extension. The product of the first amplification was diluted 1:20 $(\mathrm{v} / \mathrm{v})$ in TE 0.1X (Tris. $\mathrm{HCl} 1 \mathrm{mM}$, EDTA $0.1 \mathrm{mM}, \mathrm{pH}$ 8.0). One microliter of the dilution was used as template for a second reaction using identical conditions but with primers P16 and P45. Shorter PCR programs, using as low as $20+25$ cycles yielded essentially identical results. The nested PCR generated a single amplicon of $331 \mathrm{bp}$. For COBRA analysis, $5 \mu \mathrm{L}$ of PCR product were treated for $1 \mathrm{~h}$ with BstUI (New England Biolabs) at $60{ }^{\circ} \mathrm{C}$ or with its isoschizomer Bsh1236I (Thermo Scientific) at $37^{\circ} \mathrm{C}$, both recognizing the $5^{\prime}$-CGCG-3' sequence. In parallel, $5 \mu \mathrm{L}$ of the PCR product were subjected to incubation in the same conditions but in the absence of restriction enzyme. After digestion, samples were resolved by electrophoresis in $2 \%(w / v)$ agarose gels or, in some cases that required higher sensitivity, in $8 \%$ acrylamide/ bisacrylamide (29:1) vertical gels. After electrophoresis, gels were stained with ethidium bromide and visualized in a GelDoc XR system (Biorad). Methylation was determined by the presence of digestion products in the restriction enzyme-containing reaction that indicate the presence of originally methylated CGCG sites resilient to the bisulfite conversion. For bisulfite sequencing, $1 \mu \mathrm{L}$ of PCR product was cloned into pCR2.1-TOPO vector (Invitrogen) following manufacturer's instructions and transformed into E. coli TOP10 competent cells. Transformed cells were selected onto LB plates containing Ampicillin $(50 \mu \mathrm{g} / \mathrm{mL})$ and X$\mathrm{Gal}(40 \mu \mathrm{g} / \mathrm{mL})$. Ten to 20 white colonies were selected for plasmid preparation (QIAprep miniprep kit, Qiagen, CA). The plasmid inserts were sequenced using primers M13forward and M13-reversal (Qiagen). Array-based methylation analyses were performed on Infinium HumanMethylation450 BeadChip arrays and scanned in a HiScanSQ system (Illumina, CA), following the manufacturer's instructions. Bioinformatic analysis was performed using RnBeads package [60].

\section{Gene expression analyses}

To analyze ADAMTS19 mRNA levels, total RNA was extracted using TRIzol Reagent (Invitrogen, Life Technologies) and used as template to synthesize cDNA using SuperscriptII reverse transcriptase (Invitrogen, Life Technologies) with random hexamers for priming. We designed two primers that anneal in exon 20 (primer PB176) and exon 21 (primer PB177), generating a $242 \mathrm{bp}$ amplicon. The amplification was quantified in real time using SYBR-Green Master Mix in a Lightcycler LC480-II System (Roche, CA). After 40 cycles, the specificity of the amplification was verified by melting curve analysis, and the amplicon size was subsequently confirmed by electrophoresis in $2 \%(w / v)$ agarose gels. All reactions were performed in duplicate. Expression levels were calculated using the $2^{-\Delta \Delta \mathrm{Ct}}$ method combining both GAPDH and TPT1 as normalization genes. In all reactions, efficiency was very close to 2 within the range of concentrations assayed.

\section{Microallelotyping and array CGH analyses}

Copy number alterations were analyzed by microallelotyping using polymorphic dinucleotide microsatellite markers D5S642 and D5S2057, located 0.6 Mb centromeric and $1.8 \mathrm{Mb}$ telomeric of ADAMTS19. In some cases where both markers were in homozygosis, we also analyzed D5S2098, located $5 \mathrm{Mb}$ upstream of ADAMTS19. Primer sequences to amplify these markers were obtained from the Ensembl website [61]. PCR amplification was performed in presence of $\alpha-{ }^{32} \mathrm{P}-\mathrm{dCTP}$ and resolved in vertical electrophoresis acrylamide-bisacrylamide gels. After electrophoresis, gels were dried and exposed to X-ray films. Loss of heterozygosity was assessed in heterozygous cases by the relative change in intensity in one of the bands when comparing the normal and tumor sample. aCGH was performed using Agilent $44 \mathrm{~K}$ arrays, following the manufacturer's protocol. Copy number alterations were analyzed using Agilent Genomic Workbench, with ADM2 algorithm, threshold of 6, and Fuzzy Zero correction. Only alterations with a minimum of three consecutive probes were considered valid.

\section{shRNA design and transfection}

Three pairs of oligos coding for the shRNAs and targeting ADAMTS19 exons 3 (Exon3-F and Exon13-R), 13 (Exon13$\mathrm{F}$ and Exon13-R), and 22 (Exon22-F and Exon22-R) were designed using the web server from Life Technologies [62] (Additional file 1: Table S1). Two hundred picomole of every primer pair was annealed by incubation at $95{ }^{\circ} \mathrm{C}$ for $4 \mathrm{~min}$ and a stepwise cooling of $5{ }^{\circ} \mathrm{C}$ every 4 min down to $40{ }^{\circ} \mathrm{C}$. The annealed oligos were cloned into pSUPER (RNAi system, oligoengine) following the manufacturer's indications. After cloning, the shRNA-containing plasmids were purified and transfected into the target cells using GeneJuice Transfection Reagent (Novagen). Stable transfected cells were selected by culturing in the appropriate culture medium supplemented with $5 \mu \mathrm{g} / \mathrm{mL}$ puromycin.

\section{In vitro proliferation assay}

Cell proliferation was measured using a colorimetric test based on the capability of metabolic active cells to cleavage 
the yellow tetrazolium salt (XTT) to form a soluble orange formazan dye tetrazolium salt (Cell Proliferation Kit II XTT, Roche). Briefly, the cells were plated in 96-well microtiter plates at a density of $2 \times 10^{4}$ cells/well in Dulbecco's modified Eagle's medium (DMEM) medium with $10 \%$ fetal bovine serum (FBS) and cultured at $37{ }^{\circ} \mathrm{C}$ for $0,12,24,48$, and $72 \mathrm{~h}$ in a humidified atmosphere of $5 \% \mathrm{CO}_{2}$. Then, $50 \mu \mathrm{l}$ of XTT was added to each well and incubated for $4 \mathrm{~h}$ at $37{ }^{\circ} \mathrm{C}$ in the presence of $5 \% \mathrm{CO}_{2}$. After the incubation with XTT, the optical density was measured at 492 and $690 \mathrm{~nm}$ using a plate reader. The amount of metabolic active cells was estimated by subtracting the $\mathrm{OD}_{690 \mathrm{~nm}}$ value to the $\mathrm{OD}_{492 \mathrm{~nm}}$ value, as indicated by the kit manufacturer.

\section{In vitro anchorage-free growth assay}

Cells were suspended in growth media containing $0.3 \%$ $(w / v)$ agarose at $5 \times 10^{3}$ cells $/ \mathrm{ml}$ and layered over $1 \%(w / v)$ agar in growth media in $35 \mathrm{~mm}$ plates. The agar was allowed to solidify at room temperature for $20 \mathrm{~min}$ before incubating the cells at $37{ }^{\circ} \mathrm{C}$ and $5 \% \mathrm{CO}_{2}$. After 21 days, colonies were stained with $0.5 \%(w / v)$ Crystal Violet $(0.5 \%)$ in $10 \%(v / v)$ ethanol, then photographed, and counted. All the samples were assayed in triplicate, and in each replica, a minimum of three fields were counted and averaged.

\section{In vitro migration assay}

Cell migration was assayed by two complementary methods: scratch/wound healing assays and Transwell plates $(8 \mu \mathrm{m}$ pore size) (Millicell, Millipore). For the scratch/wound healing assays, cells were cultured until reaching confluency and then four different scratches were done using a P200 micropipette tip. The width (in $\mu \mathrm{m})$ of the scratches was measured at different positions using an automatized-capture Leica DMI 6000 B microscope. After $24 \mathrm{~h}$ of incubation, the width was measured again at the same coordinates that were previously stored in the microscope managing software. The collective migration speed was estimated dividing the difference in the scratch width by two, and then by $24 \mathrm{~h}$ (see equation in figure S7). Clumps or colonies of cells inside the scratch but disconnected from the borders of the scratch were ignored. The experiments were performed in duplicate. For the Transwell plate assays, the undersurface of the membrane was coated at $4{ }^{\circ} \mathrm{C}$ overnight with $40 \mu \mathrm{g} / \mathrm{mL}$ of Collagen I (BD Bioscience, cat N. 354236) diluted in PBS and then blocked with $2 \%(w / v)$ BSA at room temperature for $2 \mathrm{~h}$. The upper compartment was seeded with $2 \times 10^{5} \mathrm{o} / \mathrm{n}$ starved transfected cells per well in $200 \mu \mathrm{L}$ of serum-free DMEM + $0.5 \%$ BSA. DMEM + FBS (10 \%) was added in the lower chamber. Cells were allowed to migrate through the membrane for $21 \mathrm{~h}$. Cells capable of migrating through the membrane were stained with $0.5 \%(w / v)$ Crystal violet (Sigma) in $10 \%(v / v)$ ethanol. Each experiment used quadruplicate wells and, within each well, counting was performed in six randomly selected microscopic high-power fields (100x).

\section{In vitro invasion assay}

Cells stably transfected with the shRNAs were starved overnight in serum-free DMEM and then loaded into Matrigel invasion chambers (24 wells, BD Biocoat Matrigel invasion chamber, BD Biosciences) at a density of $2.5 \times 10^{4}$ cells/ well, according to the manufacturer's instructions. Cells were allowed to invade for $24 \mathrm{~h}$, and then invasive cells were fixed and stained with $0.5 \%(w / v)$ Crystal violet in $10 \%(v / v)$ ethanol and counted using an inverted microscope (Leica, McBain Instruments, Chatsworth, CA). Each experiment used quadruplicate wells, and within each well, counting was performed in six randomly selected microscopic high-power fields (100×).

\section{Analysis of the TCGA data}

Methylation status of ADAMST19 CGI was downloaded from the methHC webserver [63]. Methylation data of the TCGA ovarian cancer dataset is not included in methHC because most cases have been analyzed with the HM27K platform. Hence, this dataset was directly downloaded from the TCGA. COAD (colon) and READ (rectum) datasets were combined into a single dataset, representing colorectal carcinomas (CRC).

\section{Statistical analysis}

Statistical analyses were performed using the $\mathrm{R}$ statistical environment [64]. Association between two categorical variables was analyzed by Fisher's exact test (for $2 \times 2$ contingency tables) or chi-square test (for larger contingency tables). Normality of continuous variables was assessed using the Shapiro-Wilk test. Comparisons between two groups were performed with the Student's $t$ test for variables following a normal distribution or with the nonparametric Mann-Whitney-Wilcoxon test for variables that do not follow a normal distribution. When more than two groups were analyzed, we applied ANOVA or rANOVA analyses followed by Tukey's honest significant difference method. Trend analysis of categorical data was performed using the Cochran-Armitage test. The level of statistical significance was set at $p<0.01$, unless otherwise specified. Holm's multi-hypothesis testing correction was applied when appropriate [65].

\section{Additional file}

Additional file 1: Figures S1-7 and Table S1. Validation of the methylation alterations in ADAMTS19, array CGH analysis of Chr5, association of ADAMTS19 with clinicopathological parameters, methylation and expression of ADAMTS19 in CRC cell lines, silencing of ADAMTS19 expression using shRNA constructs, effect of ADAMTS19-silencing on growth rate and anchorage free growth, effect of ADAMTS19-silencing on collective cell migration speed, and sequence of primers used in this study. 


\begin{abstract}
Abbreviations
CGH: comparative genomic hybridization; CGl: CpG island; Cl: 95 \% confidence interval; COBRA: combined bisulfite and restriction analysis; CRC: colorectal cancer; LOH: loss of heterozygosity; MS-AFLP: methylation-sensitive amplified fragment length polymorphism; OR: odds ratio; PCR: polymerase chain reaction; TCGA: the Cancer Genome Atlas; TSS: transcriptional start site.
\end{abstract}

\section{Competing interests}

The authors declare no competing interests.

\section{Authors' contributions}

SA, BG, PGB, and MP contributed in experimental design and supervision. SA, $B G, M D D, T R L$, and $A M$ performed experiments. SA, BG, TK, KS, AS, PGB, and MP conducted analysis and data interpretation. SA, BG, and MP prepared the manuscript. All authors read and approved the final manuscript.

\section{Acknowledgements}

We thank Dr. Enric Condom from the Bellvitge University Hospital Tumour Bank of IDIBELL and Dr. August Vidal from the Department of Pathology and Experimental Therapeutics, Universitat de Barcelona, for providing ovarian cancer samples for this study. We also thank Dr. Jun Yokota for helpful discussions. This work was supported by the National Institutes of Health Grant R37CA63585 and by the Spanish Ministry of Health, Plan Nacional de I + D + I, FEDER, FIS PI09/02444 and Plan Estatal de I + D + I, ISCIII, FEDER, FIS PI12/00511.

\section{Author details}

${ }^{1}$ Institute of Predictive and Personalized Medicine of Cancer (IMPPC), Institut d'investigació en ciéncies de la salut Germans Trias I Pujol, (IGTP), Campus Can Ruti, 08916 Badalona, Barcelona, Spain. ${ }^{2}$ Sanford Burnham Prebys Medical Dicovery Institute, 10901 N. Torrey Pines Rd. La Jolla, San Diego, CA 92037, USA. ${ }^{3}$ Cancer Genetics Laboratory, IBGM-CSIC, University of Valladolid, Valladolid 47005, Spain. ${ }^{4}$ Department of Surgery, Saitama Medical Center, Jichi Medical University, 1-847, Amanuma-cho, Omiya-ku, Saitama 330-8503, Japan. ${ }^{5}$ Departament de Ciències Fisiològiques II, Campus Ciènces de Salut de Bellvitge, IDIBELL, University of Barcelona, Barcelona 08907, Spain. ${ }^{6}$ Institució Catalana de Recerca i Estudis Avançats (ICREA), Catalan Institution for Research and Advanced Studies. Pg. Lluís Companys 23, 08010 Barcelona, Spain. ${ }^{7}$ Institute of Predictive and Personalized Medicine of Cancer (IMPPC), Carretera de Can Ruti, Cami de les Escoles S/n, 08916 Badalona, Barcelona, Spain.

Received: 23 July 2015 Accepted: 24 November 2015 Published online: 02 December 2015

\section{References}

1. Ferlay J, Soerjomataram I, Dikshit R, Eser S, Mathers C, Rebelo M, et al. Cancer incidence and mortality worldwide: sources, methods and major patterns in GLOBOCAN 2012. Int J Cancer. 2015;136(5):E359-86. doi:10.1002/ijc.29210.

2. Nguyen DX, Bos PD, Massague J. Metastasis: from dissemination to organspecific colonization. Nat Rev Cancer. 2009;9(4):274-84. doi:10.1038/nrc2622.

3. Porquet N, Gout S, Huot J. The Metastatic Process: An Overview. In: Beauchemin N, Huot J, editors. Metastasis of Colorectal Cancer. vol like: Springer; 2010. p. 1-31. doi:10.1007/978-90-481-8833-8.

4. Hugen N, van Beek JJ, de Wilt JH, Nagtegaal ID. Insight into mucinous colorectal carcinoma: clues from etiology. Ann Surg Oncol. 2014;21(9):2963-70. doi:10.1245/s10434-014-3706-6.

5. Ferrario C, Basik M. Physiopathology of colorectal metastasis. In: Beauchemin N, Huot J, editors. Metastasis of Colorectal Cancer. Springer; 2010. p. 33-64.

6. Lopez-Otin C, Matrisian LM. Emerging roles of proteases in tumour suppression. Nat Rev Cancer. 2007;7(10):800-8. doi:10.1038/nrc2228.

7. Wagstaff L, Kelwick R, Decock J, Edwards DR. The roles of ADAMTS metalloproteinases in tumorigenesis and metastasis. Front Biosci. 2011;16:1861-72. doi:3827 [pii].

8. Cal S, Lopez-Otin C. ADAMTS proteases and cancer. Matrix Biol. 2015:44-46C: 77-85. doi:10.1016/j.matbio.2015.01.013.

9. Porter S, Clark IM, Kevorkian L, Edwards DR. The ADAMTS metalloproteinases. Biochem J. 2005;386(Pt 1):15-27. doi:10.1042/BJ20040424.

10. Kuno K, Kanada N, Nakashima E, Fujiki F, Ichimura F, Matsushima K. Molecular cloning of a gene encoding a new type of metalloproteinase- disintegrin family protein with thrombospondin motifs as an inflammation associated gene. J Biol Chem. 1997;272(1):556-62.

11. Fujikawa K, Suzuki H, McMullen B, Chung D. Purification of human von Willebrand factor-cleaving protease and its identification as a new member of the metalloproteinase family. Blood. 2001;98(6):1662-6.

12. Cal S, Arguelles JM, Fernandez PL, Lopez-Otin C. Identification, characterization, and intracellular processing of ADAM-TS12, a novel human disintegrin with a complex structural organization involving multiple thrombospondin-1 repeats. J Biol Chem. 2001;276(21):17932-40. doi:10.1074/jbc.M100534200M100534200.

13. Clark ME, Kelner GS, Turbeville LA, Boyer A, Arden KC, Maki RA. ADAMTS9, a novel member of the ADAM-TS/metallospondin gene family. Genomics. 2000;67(3):343-50. doi:10.1006/geno.2000.6246S0888-7543(00)96246-3 [pii].

14. Nagase T, Ishikawa K, Nakajima D, Ohira M, Seki N, Miyajima N, et al. Prediction of the coding sequences of unidentified human genes. VII. The complete sequences of 100 new cDNA clones from brain which can code for large proteins in vitro. DNA Res. 1997:4(2):141-50.

15. Colige A, Li SW, Sieron AL, Nusgens BV, Prockop DJ, Lapiere CM. CDNA cloning and expression of bovine procollagen I N-proteinase: a new member of the superfamily of zinc-metalloproteinases with binding sites for cells and other matrix components. Proc Natl Acad Sci U S A. 1997:94(6):2374-9.

16. Hurskainen TL, Hirohata S, Seldin MF, Apte SS. ADAM-TS5, ADAM-TS6, and ADAM-TS7, novel members of a new family of zinc metalloproteases. General features and genomic distribution of the ADAM-TS family. J Biol Chem. 1999;274(36):25555-63.

17. Cal S, Obaya AJ, Llamazares M, Garabaya C, Quesada V, Lopez-Otin C. Cloning, expression analysis, and structural characterization of seven novel human ADAMTSs, a family of metalloproteinases with disintegrin and thrombospondin-1 domains. Gene. 2002;283(1-2):49-62.

18. Ishikawa K, Nagase T, Suyama M, Miyajima N, Tanaka A, Kotani H, et al. Prediction of the coding sequences of unidentified human genes. $X$. The complete sequences of 100 new cDNA clones from brain which can code for large proteins in vitro. DNA Res. 1998;5(3):169-76.

19. Georgiadis KE, Hirohata S, Seldin MF, Apte SS. ADAM-TS8, a novel metalloprotease of the ADAM-TS family located on mouse chromosome 9 and human chromosome 11. Genomics. 1999;62(2):312-5. doi:10.1006/geno. 1999.6014S0888-7543(99)96014-7 [pii].

20. Somerville RP, Jungers KA, Apte SS. Discovery and characterization of a novel, widely expressed metalloprotease, ADAMTS10, and its proteolytic activation. J Biol Chem. 2004;279(49):51208-17. doi:10.1074/jbc. M409036200M409036200 [pii]

21. Rao C, Foernzler D, Loftus SK, Liu S, McPherson JD, Jungers KA, et al. A defect in a novel ADAMTS family member is the cause of the belted whitespotting mutation. Development. 2003;130(19):4665-72. doi:10.1242/dev. 00668130/19/4665 [pii].

22. Guo NH, Krutzsch HC, Negre E, Zabrenetzky VS, Roberts DD. Heparinbinding peptides from the type I repeats of thrombospondin. Structural requirements for heparin binding and promotion of melanoma cell adhesion and chemotaxis. J Biol Chem. 1992;267(27):19349-55.

23. Prater CA, Plotkin J, Jaye D, Frazier WA. The properdin-like type I repeats of human thrombospondin contain a cell attachment site. J Cell Biol. 1991;112(5):1031-40.

24. Liu YJ, Xu Y, Yu Q. Full-length ADAMTS-1 and the ADAMTS-1 fragments display pro- and antimetastatic activity, respectively. Oncogene. 2006;25(17):2452-67. doi:10.1038/sj.onc.1209287.

25. Fontanil T, Rua S, Llamazares M, Moncada-Pazos A, Quiros PM, Garcia-Suarez $\mathrm{O}$, et al. Interaction between the ADAMTS-12 metalloprotease and fibulin-2 induces tumor-suppressive effects in breast cancer cells. Oncotarget. 2014;5(5):1253-64.

26. Porter S, Scott SD, Sassoon EM, Williams MR, Jones JL, Girling AC, et al. Dysregulated expression of adamalysin-thrombospondin genes in human breast carcinoma. Clin Cancer Res. 2004;10(7):2429-40.

27. Viloria CG, Obaya AJ, Moncada-Pazos A, Llamazares M, Astudillo A, Capella $\mathrm{G}$, et al. Genetic inactivation of ADAMTS15 metalloprotease in human colorectal cancer. Cancer Res. 2009;69(11):4926-34. doi:10.1158/0008-5472. CAN-08-4155.

28. Dunn JR, Panutsopulos D, Shaw MW, Heighway J, Dormer R, Salmo EN, et al. METH-2 silencing and promoter hypermethylation in NSCLC. Br J Cancer. 2004;91(6):1149-54. doi:10.1038/sj.bjc.66021076602107 [pii].

29. Hagihara A, Miyamoto K, Furuta J, Hiraoka N, Wakazono K, Seki S, et al. Identification of $275^{\prime} \mathrm{CpG}$ islands aberrantly methylated and 13 genes 
silenced in human pancreatic cancers. Oncogene. 2004;23(53):8705-10 doi:10.1038/sj.onc.1207783.

30. Moncada-Pazos A, Obaya AJ, Fraga MF, Viloria CG, Capella G, Gausachs M, et al. The ADAMTS12 metalloprotease gene is epigenetically silenced in tumor cells and transcriptionally activated in the stroma during progression of colon cancer. J Cell Sci. 2009;122(Pt 16):2906-13. doi:10.1242/jcs.050468.

31. Jin $H$, Wang $X$, Ying J, Wong AH, Li H, Lee KY, et al. Epigenetic identification of ADAMTS18 as a novel 16q23.1 tumor suppressor frequently silenced in esophageal, nasopharyngeal and multiple other carcinomas. Oncogene. 2007:26(53):7490-8.

32. Dunn JR, Reed JE, du Plessis DG, Shaw E, Reeves P, Gee AL, et al. Expression of ADAMTS-8, a secreted protease with antiangiogenic properties, is downregulated in brain tumours. Br J Cancer. 2006;94(8):1186-93. doi:10.1038/sj.bjc.6603006.

33. Alonso S, Dai Y, Yamashita K, Horiuchi S, Dai T, Matsunaga A, et al. Methylation of MGMT and ADAMTS14 in normal colon MUCOSA: biomarkers of a field defect for cancerization preferentially targeting elder African-Americans. Oncotarget. 2015;6(5):3420-31.

34. Ehrlich M. DNA methylation in cancer: too much, but also too little. Oncogene. 2002;21(35):5400-13. doi:10.1038/sj.onc.1205651.

35. Eden A, Gaudet F, Waghmare A, Jaenisch R. Chromosomal instability and tumors promoted by DNA hypomethylation. Science. 2003;300(5618):455. doi:10.1126/science.1083557300/5618/455 [pii].

36. Feinberg AP, Vogelstein B. Hypomethylation of ras oncogenes in primary human cancers. Biochem Biophys Res Commun. 1983;111(1):47-54.

37. Baylin $\mathrm{S}$, Bestor $\mathrm{TH}$. Altered methylation patterns in cancer cell genomes: cause or consequence? Cancer Cell. 2002;1 (4):299-305. doi:S1535610802000612 [pii].

38. Greger V, Passarge E, Hopping W, Messmer E, Horsthemke B. Epigenetic changes may contribute to the formation and spontaneous regression of retinoblastoma. Hum Genet. 1989;83(2):155-8.

39. Esteller M, Corn PG, Baylin SB, Herman JG. A gene hypermethylation profile of human cancer. Cancer Res. 2001;61(8):3225-9.

40. Rountree MR, Bachman KE, Herman JG, Baylin SB. DNA methylation, chromatin inheritance, and cancer. Oncogene. 2001;20(24):3156-65. doi:10.1038/sj.onc.1204339.

41. Schuebel K, Chen W, Baylin SB. CIMPle origin for promoter hypermethylation in colorectal cancer? Nat Genet. 2006;38(7):738-40. doi:10.1038/ng0706-738.

42. Toyota M, Ahuja N, Ohe-Toyota M, Herman JG, Baylin SB, Issa JP. CpG island methylator phenotype in colorectal cancer. Proc Natl Acad Sci U S A. 1999:96(15):8681-6.

43. Widschwendter M, Fiegl H, Egle D, Mueller-Holzner E, Spizzo G, Marth C, et al. Epigenetic stem cell signature in cancer. Nat Genet. 2007;39(2):157-8. doi:10.1038/ng1941.

44. Turcan S, Rohle D, Goenka A, Walsh LA, Fang F, Yilmaz E, et al. IDH1 mutation is sufficient to establish the glioma hypermethylator phenotype. Nature. 2012;483(7390):479-83. doi:10.1038/nature10866.

45. Suzuki K, Suzuki I, Leodolter A, Alonso S, Horiuchi S, Yamashita K, et al. Global DNA demethylation in gastrointestinal cancer is age dependent and precedes genomic damage. Cancer Cell. 2006;9(3):199-207. doi:10.1016/j.ccr.2006.02.016.

46. Holemon H, Korshunova Y, Ordway JM, Bedell JA, Citek RW, Lakey N, et al. MethylScreen: DNA methylation density monitoring using quantitative PCR. Biotechniques. 2007:43(5):683-93.

47. Frommer M, McDonald LE, Millar DS, Collis CM, Watt F, Grigg GW, et al. A genomic sequencing protocol that yields a positive display of 5-methylcytosine residues in individual DNA strands. Proc Natl Acad Sci U S A. 1992;89(5):1827-31.

48. Clark SJ, Harrison J, Paul CL, Frommer M. High sensitivity mapping of methylated cytosines. Nucleic Acids Res. 1994;22(15):2990-7.

49. Putnam EA, Zhang H, Ramirez F, Milewicz DM. Fibrillin-2 (FBN2) mutations result in the Marfan-like disorder, congenital contractural arachnodactyly. Nat Genet. 1995;11(4):456-8. doi:10.1038/ng1295-456.

50. Hibi K, Mizukami H, Saito M, Kigawa G, Nemoto H, Sanada Y. FBN2 methylation is detected in the serum of colorectal cancer patients with hepatic metastasis. Anticancer Res. 2012;32(10):4371-4.

51. Tsunoda S, Smith E, De Young NJ, Wang X, Tian ZQ, Liu JF, et al. Methylation of CLDN6, FBN2, RBP1, RBP4, TFPI2, and TMEFF2 in esophageal squamous cell carcinoma. Oncol Rep. 2009;21(4):1067-73.

52. Chen $H$, Suzuki $M$, Nakamura $Y$, Ohira $M$, Ando $S$, lida T, et al. Aberrant methylation of FBN2 in human non-small cell lung cancer. Lung Cancer. 2005;50(1):43-9. doi:10.1016/j.lungcan.2005.04.013.
53. Pickup MW, Mouw JK, Weaver VM. The extracellular matrix modulates the hallmarks of cancer. EMBO Rep. 2014;15(12):1243-53. doi:10.15252/embr.201439246.

54. Fraile JM, Ordonez GR, Quiros PM, Astudillo A, Galvan JA, Colomer D, et al. Identification of novel tumor suppressor proteases by degradome profiling of colorectal carcinomas. Oncotarget. 2013;4(11):1931-2.

55. Perucho M, Peinado MA, lonov Y, Casares S, Malkhosyan S, Stanbridge E. Defects in replication fidelity of simple repeated sequences reveal a new mutator mechanism for oncogenesis. Cold Spring Harb Symp Quant Biol. 1994:59:339-48.

56. Chen TR, Dorotinsky CS, McGuire L, Macy ML, Hay RJ. DLD-1 and HCT-15 cell lines derived separately from colorectal carcinomas have totally different chromosome changes but the same genetic origin. Cancer Genet Cytogenet. 1995;81 (2):103-8. doi:0165-4608(94)00225-Z [pii].

57. World Medical Association. World Medical Association Declaration of Helsinki: ethical principles for medical research involving human subjects. JAMA. 2013;310(20):2191-4. doi:10.1001/jama.2013.281053.

58. Yamamoto F, Yamamoto M, Soto JL, Kojima E, Wang EN, Perucho M, et al. Notl-Msell methylation-sensitive amplied fragment length polymorhism for DNA methylation analysis of human cancers. Electrophoresis. 2001;22(10):1946-56.

59. Xiong Z, Laird PW. COBRA: a sensitive and quantitative DNA methylation assay. Nucleic Acids Res. 1997;25(12):2532-4.

60. Assenov Y, Muller F, Lutsik P, Walter J, Lengauer T, Bock C. Comprehensive analysis of DNA methylation data with RnBeads. Nat Methods. 2014:11(11):1138-40. doi:10.1038/nmeth.3115.

61. Suzuki K, Dai T, Suzuki I, Dai Y, Yamashita K, Perucho M. Low mutation incidence in polymorphic noncoding short mononucleotide repeats in gastrointestinal cancer of the microsatellite mutator phenotype pathway. Cancer Res. 2002;62(7):1961-5.

62. Yamamoto H, Imai K, Perucho M. Gastrointestinal cancer of the microsatellite mutator phenotype pathway. J Gastroenterol. 2002;37(3):153-63.

63. Huang WY, Hsu SD, Huang HY, Sun YM, Chou CH, Weng SL, et al. MethHC a database of DNA methylation and gene expression in human cancer. Nucleic Acids Res. 2015;43(Database issue):D856-61. doi:10.1093/nar/gku1151.

64. R Development Core Team. R. A language and environment for statistical computing. Vienna, Austria: R Foundation for Statistical Computing; 2009

65. Holm S. A simple sequentially rejective multiple test procedure. Scand J Stat. 1979:6(2):65-70.

\section{Submit your next manuscript to BioMed Central and we will help you at every step:}

- We accept pre-submission inquiries

- Our selector tool helps you to find the most relevant journal

- We provide round the clock customer support

- Convenient online submission

- Thorough peer review

- Inclusion in PubMed and all major indexing services

- Maximum visibility for your research

Submit your manuscript at www.biomedcentral.com/submit 